Archives

$6 \mid 1990$

Varia

\title{
Thèses soutenues en 1989 et 1990
}

\section{OpenEdition}

Journals

Édition électronique

URL : http://journals.openedition.org/ccrh/2876

DOI : $10.4000 /$ ccrh. 2876

ISSN : $1760-7906$

Éditeur

Centre de recherches historiques - EHESS

Édition imprimée

Date de publication : 15 octobre 1990

ISSN : 0990-9141

Référence électronique

"Thèses soutenues en 1989 et 1990 », Les Cahiers du Centre de Recherches Historiques [En ligne],

6 | 1990, mis en ligne le 20 mars 2009, consulté le 01 mai 2019. URL : http://journals.openedition.org/ ccrh/2876; DOI : 10.4000/ccrh.2876

Ce document a été généré automatiquement le 1 mai 2019.

Article L.111-1 du Code de la propriété intellectuelle. 


\section{Thèses soutenues en 1989 et 1990}

1 Jean-Philippe ANTOINE, Ars memoriae: image, espace, figure en Italie (1250-1450). (Directeur : Alberto TENENTI)

2 Jerôme BASCHET, Les justices de l'Au-delà. Les représentations de l'Enfer en France et en Italie (XII ${ }^{\mathrm{e}}-\mathrm{XV}^{\mathrm{e}}$ siècles). (Directeur : Jacques LE GOFF)

3 Robert BELOT, Lucien Rebatet ou les chemins d'un fasciste. Essai de bibliographie politique. (Directeur : Jacques JULLIARD)

4 Odile BLANC, Les usages du paraître. Le dispositif vestimentaire et les représentations du corps vêtu en France du Nord, du milieu du XIV ${ }^{\mathrm{e}}$ siècle au milieu du XV $\mathrm{XV}^{\mathrm{e}}$ siècle. (Directeur : Jean-Claude SCHMITT)

5 Philippe BUC, Potestas : prince, pouvoir et peuple dans les commentaires de la Bible (Paris et France du Nord, 1100-1330). (Directeur : Jean-Claude SCHMITT)

6 Simona CERUTTI, Naissance d'un langage corporatif. Identité citadine et métiers (Turin, $\mathrm{XVII}^{\mathrm{e}}-\mathrm{XVIII}{ }^{\mathrm{e}}$ siècles). (Directeur : Maurice AYMARD)

7 Louis CLENET, Religion catholique et Contre-révolution; essai sur les origines de l'insurrection vendéenne de mars 1793. (Directeur : François FURET)

8 Concetta CONDEMI, Le café-concert à Paris de 1849 à 1914. Essor et déclin d'un phénomène social. (Directeur : Michelle PERROT)

9 Myriam COTTIAS, La famille antillaise $d u$ XVII $^{e}$ au XIX ${ }^{e}$ siècle : étude anthropologique et démographique. Enracinements créoles. (Directeur : André BURGUIERE)

10 Jocelyne DAKHLIA, L'oubli de la cité. Récits du lignage et mémoire collective dans le Sud tunisien. (Directeur : Lucette VALENSI)

11 Colette DEREMBLE-MANHES, Etude iconographique des verrières basses de la cathédrale de Chartres. (Directeur : Jean-Claude SCHMITT)

12 Engracia DOREL-FERRE, Les colonies industrielles en Catalogne. Le cas de la Colonia Sedo. (Directeur : Louis BERGERON)

13 Patrice GUENIFFEY, La Révolution française et les élections. Suffrage, participation et élections pendant la période constitutionnelle (1790-92). (Directeur : François FURET) 


\section{Doctorats d'état}

Régine AIZERTIN, Le roman mémoriel. De l'histoire à l'écriture du "hors-lieu". (Directeur : Marc FERRO)

Robert ILBERT, Alexandrie. Espace et société (1830-1930). (Directeur : Lucette VALENSI)

Claudie WEILL, Les étudiants russes en Allemagne, 1900-1914. (Directeur : Marc FERRO)

\section{Addendum}

Le texte de Lucette VALENSI, Comment prouver la mort du roi. Le cas de Sébastien de Portugal, publié dans les Cahiers du $C R H, \mathrm{n}^{\circ} 5$, avril 1990, pp. 1-11, a été présenté au $\mathrm{x}^{\mathrm{e}}$ Congresso Internazionale di Studi Antropologici sur la Prova (la preuve) qui s'est tenu à Palerme du 14 au 16 décembre 1989. Par ailleurs, depuis la rédaction de cette communication, le roi 
Sébastien a fait l'objet d'une étude de Y.M. BERCE, Le Roi caché: sauveurs et imposteurs. Mythes politiques populaires dans l'Europe moderne, Paris, Fayard, 1990, ch. 1. 